\title{
Dos miradas a Alándalus, desde el Nuevo Mundo
}

\section{Two looks to Alandalus coming from the New World}

\author{
Rosa Isabel MARTíNEZ LILLO \\ Universidad Autónoma de Madrid \\ dedinap@yahoo.es
}

Recibido: 31 de enero de 2015

Aceptado: 30 de junio de 2015

\section{RESUMEN}

La mirada de los poetas chilenos de origen árabe Emilio Mohor Zummers (1920-2002) y Olga Lolas Nazrala (1927) hacia Alándalus.

Palabras clave: Mahyar, poetas chilenos de origen árabe, Alándalus.

\begin{abstract}
The look of the Chilean poets of Arab origin Emilio Mohor Zummers (1920-2002) and Olga Lolas Nazrala (1927) on Alandalus.

Keywords: Mahyar, Chilean poets of Arabic origin, Alandalus.
\end{abstract}

SUMARIO: 1. Introducción, 2. Una aproximación al Mahyar meridional, 2.1. Apuntes teóricos, 2.2. Dos testimonios, 3. El caso de Chile: la lejana mirada de esos isleños australes, 3.1. La llegada a Chile, 3.2. Generaciones literarias, 3.3. Aproximación a Alándalus, 4. Dos Alándalus poéticas: Emilio Mohor Zummers (1920-2002) y Olga Lolas Nazrala (1927), 4.1. Emilio Mohor Zummers, 4.2. Olga Lolas Nazrala, 5. Conclusiones: y queda... 


\section{INTRODUCCIÓN}

Continúan las miradas a Alándalus desde lares y tiempos diferentes. A ella se asoman, de nuevo, poetas, novelistas, estudiosos deseosos de deambular por sus recovecos, degustar sus sabores, escuchar sus palabras, para evocar, en fin, aquello que encuentra cada uno de ellos; todos miran, miramos, a Alándalus.

Acaso estas miradas a Alándalus vayan conformando, también ellas, una nueva realidad, la realidad esencialmente del ¿cómo? que, en el mundo literario, adquiere singular relevancia.

Doblemente singular resulta este ¿cómo? desde el Nuevo Mundo chileno, desde esta América austral en que los escritores, tanto poetas como prosistas, se tornan verdaderos artífices del adjetivo, dueños sin par del epíteto; autores-magos de la calificación, nunca en detrimento de la esencia, del núcleo, del sustantivo, sino, muy al contrario, forjadores de términos y realidades trascendentes y trascendidas allende los mares, allende nuestro cálido y mesurado Mediterráneo. Singular resulta, por una parte, porque se encuentra íntimamente vinculada al hecho de la emigración en sí, porque se trata de una mirada de árabes «trasplantados» — en boca de la propia Olga Lolas-, de árabes asentados en otro continente, en el Nuevo Mundo; más aún, porque la emigración en Chile corrió y corre diferente suerte al resto de la emigración en América'; y singular, por otra, al involucrarse en una realidad social y literaria en particular, la chilena, que poco comparte con los países vecinos².

Planteado así el estudio - centrado en la mirada a Alándalus de dos poetas del S. $\mathrm{XX}$, chilenos de origen palestino - ilustrativo será comenzar con unas palabras sobre el hecho de la emigración árabe a la América meridional, continuar con el caso chileno - en su doble vertiente, social y literaria - para terminar con la perspectiva de los poetas referidos; perspectiva que será expuesta a partir del análisis de sus propios poemas.

Para terminar, el último apartado se presenta a modo de conclusiones.

\section{UNA APROXIMACIÓN AL MAHYAR MERIDIONAL}

Acerquémonos a este lugar de la emigración desde dos ópticas: en primer, con unos apuntes teóricos, referidos a cuestiones generales, $y$, en segundo, a partir de la pro-

\footnotetext{
${ }^{1}$ Si bien el punto de partida de tal emigración es básicamente el mismo, el Levante árabe, ya los momentos de olas migratorias van diferenciándose en los diversos países de llegada; en este sentido, y a modo de ejemplo, es significativo cotejar el fenómeno en Chile — donde, a excepción de casos aislados de refugiado palestinos, la emigración es prácticamente nula hoy en día - con el de México, a donde sigue llegando, particularmente desde Líbano.

${ }^{2}$ En realidad, y a pesar de que usualmente desde Europa tendemos a ver la realidad de Latinoamérica como un todo homogéneo, cada realidad geográfica-cultural tiene su idiosincrasia. Solemos creer que la lengua española es el vínculo por excelencia, y quizá sea así, pero conociendo in situ pueblos y lugares somos conscientes de la heterogeneidad y diversidad imperantes.
} 
pia experiencia de dos testigos vivos: el novelista chileno Walter Garib (1933) y el argentino Kamil Manzur (1938).

\subsection{APUNTES TEÓRICOS}

A pesar de la importancia que tiene la presencia árabe en América Latina, los estudios realizados acerca del tema siguen siendo escasos. Los pocos trabajos que existen se limitan, según nuestros conocimientos, en cubrir determinados países, salvo un estudio editado por la UNESCO en 1977, y que abarca la presencia de las colonias árabes en catorce países latinoamericanos. Sin embrago, el dinamismo que caracteriza las comunidades árabes actualmente en América Latina, y los acontecimientos que tuvieron lugar en su seno en los últimos años, convierten en necesidad la aparición de nuevos trabajos $[\ldots]^{3}$.

Con estas palabras introduce el profesor Abdelhuahed Akmir un sólido libro sobre la presencia árabe en América Latina; una primera llamada de atención atrae nuestra mirada: a pesar de tratarse de una cuestión realmente trascendente, el tema no ha sido tratado cuanto merece, de tal modo que todavía hay mucho por estudiar, mucho por hacer.

Sin bien, tal y como nos indica el eminente historiador en dicho prólogo, es pertinente hablar de un proceso de asentamiento en la tierra de acogida en que la integración social, la aportación económica, la participación política y la fundación de asociaciones no difiere mucho de una región a otra, la verdad es que, también como él mismo apunta más adelante, cada país tiene sus particularidades; cada realidad alberga su propia idiosincrasia y características.

El punto de partida es fundamentalmente uno: el Levante árabe; las causas sociales, económicas y religiosas o de confesión- básicamente afines, y así los tiempos de las olas migratorias, aun sin ser exactamente los mismos.

Si profundizar en tal aspecto, la emigración árabe a América Latina, no ha lugar en este trabajo, obligado es apuntarlo reincidiendo en su relevancia. Muy sucintamente, entonces, sería necesario apuntar al menos cinco cuestiones básicas:

En primer lugar, y en cuanto al lugar en sí de la partida, habremos de realizar que, a pesar provenir de una zona en concreto, fundamentalmente el Levante o la histórica Gran Siria, el Shām, la vida no se mueve al mismo ritmo en una aldea palestina que una ciudad libanesa, pongamos por caso; ni las pautas sociales son exactamente las mismas, ni los usos; ni siquiera las hablas locales.

En segundo lugar, la confesión. Si bien la mayoría de los emigrantes son cristianos (ortodoxos o maronitas principalmente) de confesión, también existe una minoría musulmana (dependiendo de las zonas, ortodoxa o heterodoxa, siendo las tendencias heterodoxas las más seguidas, preferentemente en el norte de Argentina). El hecho de la confesión, mejor aún, del grado de profesión de fe, valga la expre-

\footnotetext{
${ }^{3}$ AKMIR, Abdelhuahed (coord.), Los árabes en América Latina (Historia de una emigración), Madrid, 2009, 1.
} 
sión, incide directamente en la dimensión lingüística —a mayor vínculo con la realidad religiosa, mayor vínculo con la realidad lingüística del árabe más «correcto», el fușhà-. Ahora bien, en general, toda la emigración de origen árabe va a conocer, en menor o mayor grado, algo de su lengua - al menos de la variante hablada en su lugar de origen- y la va a emplear en el ámbito doméstico principalmente el gastronómico-, el artístico/musical, y aquel relacionado con fiestas y tradiciones.

En tercer lugar, el estatus social. Difícil, muy difícil resulta saber a ciencia cierta cuál era el estatus social de los emigrantes — básicamente de los primeros, aquellos que llegan a finales del S.XIX y antes de 1920-, pero, grosso modo, y como coinciden en afirmar gran número de estudiosos ${ }^{4}$, se ha extendido sobremanera la mirada legendaria (que afirma se trataba de grupos sociales de bajo nivel social). Según los documentos consultados - Centro de Estudios Árabes de la U. de Chile, Biblioteca del COLMEX, Biblioteca de la Universidad da San Miguel de Tucumán, Biblioteca particular de Matías Rafide, Biblioteca particular de Velia Chuaqui, Biblioteca particular de Indiana-Rita Jorrat, entre los más relevantes- y los testimonios de familiares y allegados — Marcela Zedán, Eugenio Chahuán, Olga Lolas, Walter Garib, Matías Rafide, Naín Nómez, Carlos Duguech, Adela Chedid, Kamilo Manzur y Bárbara Jacobs, entre otros-, si bien todo apunta a la capacidad de trabajo de estos emigrantes, a su sacrificio diario, su esfuerzo cotidiano, no se llama la atención sobre el posible origen realmente humilde. Así, y siempre teniendo en cuenta las particularidades, el estatus social sería de nivel medio.

En cuarto lugar, el punto de llegada, la tierra de acogida. Una vez arribados al Nuevo Mundo - de esta emigración los puertos de llegada son, básicamente, Brasil, Argentina y el México atlántico (Veracruz) - el paraíso en la tierra, el lugar de las posibilidades, los emigrantes, asesorados o ayudados por un paisano o familiar ya asentado en América, se instalaban en el sitio elegido; allí es donde, con el tiempo, irían ubicándose los nuevos emigrantes, del mismo modo, familiares y/o allegados.

Mas si cada lugar de partida tenía, tiene, su propia idiosincrasia, también cada lugar de llegada guardaba, y sigue haciéndolo, sus características a todos los niveles. Instalarse al norte de Argentina, por ejemplo, tiene poco que ver con instalarse en la chilena San Felipe; y, dentro de una misma realidad geográfica, instalarse en la mexicana Puebla de principios del XX muy diferente sería de hacerlo hoy en día en México D.F.- - en donde sigue habiendo un manifiesto flujo migratorio, preferentemente desde Líbano-.

Y finalmente, en quinto lugar, los tiempos de las olas migratorias. Naturalmente, tomando el testigo donde se quedó en el punto cuarto, los momentos también son significativos y guardan un vínculo directo con el lugar de llegada. Si, a grandes rasgos, puede hablarse de una ola migratoria pionera a finales del XIX, tras la Pri-

${ }^{4}$ HAUSER, Karim y GIL, Daniel (editores), Contribuciones árabes a las identidades iberoamericanas, Madrid, 2009. 
mera Guerra Mundial se produce uno de los principales hitos en este sentido; de manera afín, tras la creación, en 1948, del Estado de Israel en tierra palestina. En el caso concreto de Chile, país de ambos poetas tratados y la principal tierra de acogida de emigrantes de origen palestino, las olas migratorias se detendrán a partir de 1960, año en que, como indica el profesor Agar, la llegada de emigrantes es ya prácticamente inexistentes.

Tras estos cinco aspectos de índole general, en el campo puramente literario, y al margen de nombres aislados, hablaría únicamente de una asociación literaria en América Latina reconocida a nivel internacional: El Círculo Andalusí (Al- 'Ușba alAndalusiyya), constituida formalmente el 5 de enero de 1933 en la brasileña Sõo Paulo y desaparecida veinte años después. Dicho grupo, aparte la reconocida o no calidad literaria de varios de sus componentes, se caracteriza, entre otros, por dos elementos a resaltar: el vínculo con la realidad de origen - Siria y Líbano principalmente - gracias a la vía natural del Atlántico, y, lo que es de suma importancia, la utilización de la lengua árabe.

Con el paso del tiempo, y a excepción de otros grupos literarios - ubicados en Brasil, Argentina y México eminentemente - el uso de la lengua árabe se va a quedar relegado a ciertos ámbitos restringidos, como se apuntaba antes, y básicamente se van a utilizar las variantes orales originarias.

En el caso particular de Chile, a partir de 1920 la lengua árabe dejará de utilizarse en su dimensión escrita, lo que, por una parte, quizá ayudara a la integración social — pues el idioma utilizado desde entonces en periódicos y revistas sería el español o castellano-, pero, por otra, no ayudó a fomentar los vínculos literarios con la tierra de partida.

\subsection{DOS TESTIMONIOS}

Para terminar este apartado, escuchemos dos testimonios de hijos de emigrantes árabes: Walter Garib (Requínoa, Chile, 1933) y Kamilo Manzur (Monteros, Argentina, 1938).

Compartiendo ambos el amor a la literatura, al arte y la cultura en términos generales, se aprecia una diferencia fundamental en la dimensión que ahora nos ocupa: el conocimiento y uso de la lengua árabe.

El primero, el conocido novelista Walter Garib, empieza su relato remontándose a las historias vividas con sus abuelos, llegados de Palestina:

El hecho de haber vivido con mis abuelos hasta los 12 años, marcó desde niño mi existencia. La comida, costumbres, el trato familiar impregnados de arabidad, ayudaron a mi formación. Me seducía asistir a las reuniones de mis abuelos con sus amigos, y me deleitaba escuchar sus historias. A veces contadas en árabe y otras en castellano. Si no las entendía, pues mi abuela me las refería después. De ahí creo surgió mi pa-

\footnotetext{
${ }^{5}$ AGAR, Lorenzo, «Inmigrantes y descendientes de árabes en Chile: adaptación social» en Los árabes en América Latina (Historia de una emigración)..., 109.
} 
sión por escribir. Los cuentos de las Mil y Una Noches -libro que después conocí de adulto- los escuchaba a diario, pues como mis abuelos eran analfabetos, hablaban a través de ellos. Como los árabes son una raza de fabuladores, recibí de herencia esta cualidad. Hasta la edad de 15 años estuve ligado a la religión católica, aunque mis abuelos eran ortodoxos, pero al ingresar al Internado Nacional Barros Arana, de inspiración laica, dejé de practicarla.

Mis abuelos hablaban el árabe de los campesinos y mis padres sabían algunas palabras y lo hablaban con alguna dificultad. Años después, mi padre conoció a un palestino muy culto, quien le enseñó a hablarlo. Mis padres continuaron con la tradición, lo que se percibía en las comidas, amistades y formas de vivir.

En nuestro hogar recibimos por norma a escritores y pintores, muchos de ellos de origen árabe. Nos relacionamos con ellos en distintas instancias. No hablamos árabe, pero sí a nuestra mesa a menudo hay comida árabe, pues Lenka ${ }^{6}$ es una diestra cocinera. Estamos integrados al país donde hemos nacido, sin embargo, siempre nos preocupamos de hablar de nuestros orígenes, pues nos sentimos orgullosos de ser nietos de inmigrantes.

Mientras vivíamos con Lenka en España-Madrid durante 1995, fuimos a Palestina a conocer a nuestras raíces, a la familia que se hallaba en Beit Saour. Experiencia única donde pudimos enfrentarnos a la realidad de un pueblo laborioso, inteligente, provisto de una cultura milenaria, dominado por las potencias imperialistas. Nosotros por lealtad a cualquier pueblo oprimido, apoyamos su causa de emancipación y trabajamos en beneficio de su liberación ${ }^{7}$.

E1 segundo, Kamilo Manzur, director del Centro Árabe de Montero (Argentina) desde 1989 hasta 2000 y amante donde los haya de las letras, comienza sus palabras refiriéndose al padre, llegado de Siria:

Desde niños mi padre nos enseñó la cultura del trabajo, en el año 1945 teníamos un almacén en el que con 7 años de edad me asignaban la tarea de vender cigarrillos y pilas para linternas en un sector del negocio. Mi papá siempre decía que una vez había escuchado en Radio Moscú que "a los niños hay que mantenerlos siempre entretenidos, para que no influyan sobre ellos ideas extrañas".

Mi padre era un ferviente defensor de su arabismo, y como pretendía volver a su pago natal nos trajo un profesor de idioma árabe; y le construyó a él y a su familia una casa a 50 metros de la nuestra. El profesor se llamaba Yussef Sarme, quien más tarde fue editor de una conocida revista mensual poético-literaria bilingüe (árabe - castellano), denominada "Al- Mawahib" ("Los Dones"). Aun cuando era muy pequeño memorizaba las obras literarias que mi profesor intercambiaba con otros inmigrantes apasionados por la poesía. Entre las que aún recuerdo se encontraban obras tales como "Majnun Leyla", "Ruba3iat"; de Elias Farhat, las poesías del Mutannabbi, y de Elia Abu Madi, Sha3er al Qarawi, entre los grandes poetas del mahjar. Comencé en ese entonces a prestar atención y memorizar las recitaciones del Corán. Mi madre, que no sabía leer ni escribir; me pedía que le recite los rezos que aprendía.

${ }^{6}$ Lenka Chelén Franulič, su esposa y conocida artista; hija de madre croata y padre libanés.

${ }^{7}$ MARTÍNEZ LILLO, Rosa-Isabel, Viajando en la memoria: de oriente al Nuevo Mundo, (en prensa). Se reproduce tal y como ha sido redactado por el autor, así como el relato ulterior. 
En el seno de mi familia se hablaba únicamente el árabe, ya que mis padres decían que "para el castellano, ya iba a tener tiempo". Cuando ingresé al primer grado de la escuela, casi no hablaba en español por lo que las maestras nos pedían a mí y a mis hermanos que dejemos de lado un poco el árabe para asimilar mejor el lenguaje.

Mi arabidad sigue intacta porque es parte de mi historia, de mis sentimientos y pensamientos, a pesar de que la primera generación de árabes inmigrantes en la Argentina ya no está entre nosotros. Desde mi nacimiento me he nutrido de la religiosidad, las comidas, la manera de pensar, las poesías, los relatos. Mi madre desde niño me cantaba en árabe para hacerme dormir y todavía resuenan en mi alma sus pedidos a Dios cuando me enfermaba: “ ia 3aine, ia ru7e, $\iota$ porque Dios no me castiga a mí en tu lugar?”. Eso es parte de mi vida y mi espíritu y no lo puedo olvidar. Cualquier persona que me ve, me ve como un árabe. Cuando digo que nací en Monteros, me miran extrañados!

A veces me pongo a tararear en soledad canciones populares argentinas que traduzco al árabe. Yo soy un argentino de origen árabe. Con sentimientos genuinos hacia mi país y hacia el país de mis padres ${ }^{8}$.

Ambos, sí, de origen árabe, de generaciones a penas distanciadas por cinco años, y con un sentimiento potente de arabidad; ambos, en realidad, con diferentes vivencias respecto a la lengua árabe.

Desde tal perspectiva, el uso de la lengua árabe, un hecho constatamos: dedicado en cierto modo al activismo político el primero de ellos, Walter Garib, desconoce el árabe, a pesar de ser escritor reconocido y tratar diariamente con las letras y la literatura; Kamilo Manzur, de origen sirio, hombre de fe -musulmán alauí-, tiene conocimientos del árabe más culto realmente a gran nivel.

Naturalmente, sería necesario tomar más ejemplos para llegar a unas conclusiones contundentes y rigurosas, pero simplemente tomemos ambos testimonios para reincidir en la cuestión del lugar de acogida y la posterior y deseada inserción social. El uso del árabe ha corrido distinta suerte, repito, eminentemente en función del lugar de llegada y posterior integración social y, no hay que olvidarlo, en función del vínculo con la dimensión religiosa - obviamente haciendo caso omiso de las necesidades profesionales, en el caso de quienes se dedican a la enseñanza del idioma-.

\section{EL CASO DE CHILE: LA LEJANA MIRADA DE ESOS ISLEÑOS AUSTRALES}

Para exponer la experiencia de los autores chilenos preciso será detenernos primeramente en tres puntos de partida: los autores de origen árabe, que van conformando el llamado Mahyar literario en el país andino, las generaciones literarias del país y, por último, la aproximación en sí al tema, a nuestra Alándalus.

\subsection{LA LLEGADA A CHILE}

Invierno de 1903. Un palestino llegaba a San Felipe. Tenía 23 años. Venía solo. Su compañero de andanza se quedó en Santiago. Era el único palestino en el pueblo. Sa-

\footnotetext{
${ }^{8}$ MARTÍNEZ LILLO, Rosa-Isabel, Viajando en la memoria: de oriente al Nuevo Mundo, (En prensa).
} 
bía unas palabras en español y con ellas como único bagaje ingresó a una cultura, bien otra a la de su pueblo de costumbres milenarias: Beit Jala, a unas escasas millas de Jerusalén. Luego de unos meses de incursiones, no con la mochila, no, sino con un canasto de "cosa tenda", le cupo en suerte dar con San Felipe. El encantamiento fue inmediato. Tuvo muy buena llegada. Lo recibió el entonces alcalde de la ciudad, don Francisco Soza, como si fuera un antiguo conocido, y le arrendó un local para instalarse en la calle Prat. Nunca olvidó ni dejó de agradecer esta confianza con que fue acogido. Allí empezó a labrarse día a día su destino, de una "transparencia y probidad" admirable.

Le gustó tanto el pueblo que se fue quedando. Solo una vez volvió a su tierra. Salió para regresar casado con una hermosa joven de su mismo pueblo. Duró más de cien años su carnet de permanencia 9 .

Sirva este inicio, relatado por la pluma de la propia Olga Lolas Nazrala ${ }^{10}$, principio del periplo chileno.

Llega el padre de Olga al pueblecito de San Felipe y allá se asienta hasta que termina sintiéndose, como toda su familia, chileno hasta la médula — si bien el poso de arabidad nunca habrá de desaparecer-.

Pero, como se indicó anteriormente, no todos los emigrantes corrieron la misma suerte.

En efecto, y a modo de ejemplo, la experiencia del pionero en Santiago, el sirio de origen Benedicto Chuaqui (1895-1970) ${ }^{11}$, fue bien distinta, a pesar de que él siempre la contara con buena disposición, e incluso en tono jocoso en muchas ocasiones:

Necesitaba comprar carbón y pregunté a un vecino el nombre español de este combustible. Para estar más seguro lo escribí en un papel. Pero el bribón me hizo poner cabrón, en vez de la palabra verdadera. Fui repitiéndola hasta llegar al depósito de leña, cuyo dueño era un hombre de mal talante, chato, obeso, con la nariz granujienta y roja. Estaban con él en ese momento, algunas personas que, al oírme decir: Véndame cabrón, les dio un verdadero ataque de risa. En cambio, al vendedor le faltó poco para darme una paliza ${ }^{12}$.

En términos globales, y a modo de resumen, la emigración árabe en Chile, es básicamente de origen palestino, cristiana ortodoxa - aunque paulatinamente se va convirtiendo al catolicismo - , de un nivel cultural medio, y que, a pesar de dedicarse inicialmente a los pequeños negocios de textiles, compra venta de objetos de mercería y afines, se va convirtiendo en un «grupo» social pudiente, dedicado en

\footnotetext{
${ }^{9}$ MARTÍNEZ LILlO, Rosa-Isabel, Alándalus/España desde la otra orilla: el Pacifico chileno, Coquimbo, Chile, 2013, 27-28.

${ }^{10}$ En cuanto a la trascripción del árabe, sigo las pautas de Anaquel con la excepción de la letra "shīn", que transcribo "sh"; los nombre de autores latinoamericanos y los términos españolizados los escribo como aparecen en las fuentes o como los utilizan ellos mismos.

${ }^{11}$ ÁGREDA, Fernando, "Benedicto Chuaqui (1895-1970) y el diálogo árabe-íbero-americano" en Amanecer, febrero (2003), 71-3. Obligada es la lectura de RAFIDE, Matías, Escritores chilenos de origen árabe, Santiago de Chile, 1989.

${ }^{12}$ MARTÍNEZ LILLO, Rosa-Isabel, Alándalus..., 71-72.
} 
gran manera a la prensa - buena prueba de ellos son los periódicos $A l-S h a b i ̄ b a, ~ A l-$ Murshid, Al-Wațan/La Patria, Al-Ișlāh/La Reforma, Oriente y Mundo Árabe ${ }^{13-}$, la educación, la pedagogía, la literatura, las humanidades en general, así como a la medicina e ingeniería.

\subsection{GENERACIONES LITERARIAS}

Estos primeros literatos emigrantes, que en un hondo deseo por chilenizarse sin demora adoptan desde muy pronto la lengua española - dejando las variantes dialectales árabes para entornos concretos, como la gastronomía y la música básicamente-, habrán de incluirse en las generaciones del país de acogida, Chile, para ser valorados, tanto en análisis como en sentimiento, en todo su esplendo.

Así, habrán de sumergirse en la realidad de América Latina de principios del siglo pasado:

Durante el primer tercio del siglo XX, la historia de América Latina estuvo marcada por dos tendencias dominantes; por un lado, el desarrollo de una conciencia nacional y latinoamericana, producto directo de la consolidación social y el ascenso político de las capas medias, y, por otro, la intervención directa de los países centrales en los asuntos económicos y políticos de una periferia que no se resignaba a perder como área de influencia propia. La producción artística y literaria de la época representa y estimula un proceso de cambio que se reproduce con distintas repercusiones en el continente y en Chile ${ }^{14}$.

En dicha coyuntura conviven los poetas que traemos a colación: Emilio Mohor Zummers (1920-2002) y Olga Lolas Nazrala (1927); ambos pertenecientes a la llamada Generación de los 50 o 57 que, literariamente hablando, es receptora de autores norteamericanos y europeos, como Virginia Woolf, Graham Greene, Franz Kafka, William Faulkner y Marcel Proust, entre otros, y caracterizada por tratar de encontrar nuevas técnicas de expresión, a la par de tender hacia cuestiones de corte metafísico y existencial.

Una última apreciación: Chile está considerada, por historiadores y sociólogos, una isla cuyas principales orillas son La Cordillera, de una parte, y el Océano Pacífico, de otra. Acaso este sentimiento de insularidad ${ }^{15}$ no haga sino aumentar la nostalgia - elemento indispensable en los autores del Mahyar-, las nostalgias, en los poetas de este trabajo. Sea como fuere, y siguiendo las palabras del singular Andrés Sabella, también de origen árabe, la nostalgia define al chileno.

${ }^{13}$ Dichos periódicos fueron microfilmados y estudiados por la profesora Carmen Ruiz. Véase AMO, Mercedes del, "La literatura de los periódicos árabes en Chile", en Miscelánea de Estudios Árabes y Hebraicos, Vol. 55 (2006), 3-35 y PACHECO, J. Antonio, "La prensa árabe en Chile: Sueños y realidades en un mundo nuevo", en Miscelánea de Estudios Árabes y Hebraicos, Vol. 55 (2006), 277-322.

${ }^{14}$ NÓMEZ, Naín, Poesía chilena contemporánea (Breve antología crítica), Santiago de Chile, 1998, 9-10.

${ }^{15}$ MIHOVILOVIČ SUÁREZ, Jorge-Roberto, El último ciudadano, (en prensa). 


\subsection{APROXIMACIÓN A ALÁNDALUS}

Alándalus, en tanto que paraíso perdido, tierra de llegada del primer omeya pero también tierra de pérdida del último rey nazarí, será uno de los temas recurrentes de muchos poetas de origen árabe asentados en América.

Mencionado el grupo del Círculo Andalusí, ¿de qué otra manera más patente sería posible recalcar la importancia de Alándalus, sino como bandera del propio grupo?

No obstante, hay que tener en cuenta un hecho fundamental a la hora de sumergirnos en el tema de Alándalus: la dimensión cronológica. Si bien Alándalus es piedra angular en numerosos poetas emigrados a América, aquellos de la primera emigración son quienes han vivido la experiencia andalusí en su propia carne, en tanto que emigrantes; es decir, han vivido Alándalus como tierra de emigración:

Estos poetas, en definitiva, son seres trasplantados de una tierra a otra. En la raíz de su obra latirá virtualmente siempre esta dolorosa experiencia compañera, que le otorgará una dimensión psíquica inevitable. Además de emigrante, este individuo sensible se siente con frecuencia desterrado, casi inerme ante el extrañamiento y la expatriación ${ }^{16}$.

Conforme vaya aumentando la lejanía, en tiempo y espacio, irá aumentando la distancia con respecto a la vivencia andalusí. Lo que significa que autores, poetas, de segunda generación guardarán unos vínculos para con Alándalus basados, fundamentalmente, en la recreación de lo imaginado, de lo evocado por los predecesores. Si a tal lejanía cronológica añadimos la espacial, la geográfica, no resultará complicado explicarse — isi es que la poesía, el arte en general, precisa de explicaciones racionales - porqué la Alándalus cantada por los poetas chilenos, Emilio Mohor y Olga Lolas, es sustancialmente una Alándalus onírica, de idea y ensoñación.

De tal modo que la experiencia chilena, tanto en ámbitos académicos como literarios, no está sino corroborando aquello que acaece en diversos lares de América y ya a partir de los autores de segunda generación: Alándalus es, antes que realidad histórica, vivencia y percepciones personales.

Alándalus es eminentemente evocación, símbolo, perspectiva, subjetividad...en ocasiones vinculada con a España, pero en la mayoría de ellas asociada directamente a Andalucía.

Experiencia única resulta preguntar a los propios poetas sobre Alándalus, pues a menudo la respuesta esperada - cualquier respuesta - vuelve a convertirse en pregunta: ¿A qué te refieres con Alándalus?

Cada escritor chileno de origen árabe vive su propia Alándalus, la recrea, la evoca y la dibuja de modo personal; así los poetas, esos artífices más puros de la metáfora del alma, la poesía, parafraseando al colombiano de origen libanés Giovanni Quessep Esguerra (1939).

Veamos ya cómo se acercan a Alándalus los dos poetas chilenos.

${ }^{16}$ MARTÍNEZ MONTÁVEZ, Pedro, Al-Ándalus, España, en la literatura árabe contemporánea, Madrid, 1992, 72. 


\section{DOS ALÁNDALUS POÉTICAS: EMILIO MOHOR ZUMMERS (1920- 2002) Y OLGA LOLAS NAZRALA (1927)}

\subsection{EMILIO MOHOR ZUMMERS}

Este poeta, de origen palestino, nace el 20 de mayo de 1920 en la ciudad de Concepción. Tras licenciares como médico cirujano en 1945 en la Universidad de Chile, y haber colaborado con la causa árabe en tanto que editor y administrador ${ }^{17}$, continúa compaginando su carrera profesional con la literaria. Y no sólo se compromete con la causa árabe, sino con aquella de su entorno más cercano: colabora como crítico literario en el diario La Nación de Santiago y es socio honorario de la Cooperativa Internacional de Escritores de Montevideo.

Como escritor, destacan sus cuentos Tristeza peruana, premiado por la Colección Tichauer en 1976, Ensueño, La aldea de Zebdane y Noche rusa, y sus divanes Pulso (1960), Oda al Libano (1976), y el inédito Semilla del tiempo; su novela Tierra verde tampoco llegaría a ver la luz.

Pocos datos existen de su vida, pero se sabe que entre 1952 y 1953 viajó por varios países de Europa, África y América del sur.

De entre sus poemas, encontramos dos en que recrea este espatiempo18, Alándalus, desde una mirada un tanto estereotipada, exótica, imbuida de su propia perspectiva poética, pues, como observa el Profesor egipcio Lufti Abdel Badi «lleva un mensaje solidario y humano, y es posible captar en él un exótico sabor de amargura y felicidad $\rangle^{19}$.

Así canta Emilio Mohor a sus orígenes, vinculándolos con la Península, en este poema titulado "El árabe" ${ }^{20}$, que escribió a los quince años y publicó en el prestigioso periódico Mundo Árabe el 28 de septiembre de 1935:

Sentado a la sombra, bajo una palmera,

El árabe triste observa el paisaje,

Y entre dientes reza la oración sincera,

Mientras en lo alto murmura el follaje...

Sus ojos preñados de melancolía,

Tienen de los ciervos el mirar sombrío,

Estos se humedecen al caer el día,

Llorando su pena, igual como el río...

Construye el pasado de gloria i grandeza

Que ha pocos siglos asombrara al mundo,

Y en su inmensa pena y su honda tristeza

Añora el pasado con dolor profundo.

${ }^{17}$ Dirigió la Revista del Centro de Alumnos de la Escuela de Medicina de la Universidad de Concepción y el Instituto Chileno-Árabe de Cultura durante varios años.

${ }^{18}$ Tomando el término del autor iraquí `Abd Al-Mālik Nūri.

${ }^{19}$ RAFIDE BATARCE, Matías, Escritores chilenos de origen árabe..., 161.

${ }^{20}$ Los poemas quedan transcritos tal y como aparecen en las fuentes consultadas. 
Todo lo ha perdido, la florida España,

Llena de jazmines, nardos y claveles,

Y en su afán perdido cantando se engaña,

Pues a veces cree ver bellos bajeles...

Bajeles que dejan atrás la ribera

Del mar y llegan al monte que un día

El guerrero Tarik su nombre le diera,

Dándole a esa tierra su melancolía...

Sufre en su delirio la ficción de un sueño,

Modela legiones de bravos guerreros

Que el mar cruzan en un loco ensueño,

Llegando a la Iberia en breves veleros...

Nómada versátil que pasas la vida

Soñando en la arena bajo un sol de fuego,

Participa en algo tu ilusión perdida

Conmigo; te veo aunque esté yo lejos...

Tu pena es mi pena, tu gloria la mía,

En mi alma de criollo se anida tu tierra,

Yo sigo tus pasos en tu fantasía,

A donde tú vayas, al mar o a la sierra...

Por eso yo quiero que juntos vaguemos,

Por anchos senderos llevando la luz,

La luz de tu pueblo y siempre lo amemos,

Como amó el Peregrino que llevó la Cruz.

En este poema de ocho cuartetas dodecasílabas, esto es, de estructura clásica, ¿cuáles son las constantes en la mirada de Mohor?

En primer lugar, y atendiendo a la descripción del principio, nos ubica espacial y temporalmente: el árabe se encuentra bajo la sombra de una palmera para resguardarse del sol. Ese árabe, acaso desilusionado de su presente, retrocede en el tiempo y observa la historia: la gloriosa historia de los árabes, cuando Tarik llega a la Península y deja su huella en lo que será Gibraltar.

Allende los mares hay otro hombre, un criollo, observando la escena: él, como el árabe, también tiene algo de extranjero, de exiliado, y comparte con el árabe ese sentimiento de desilusión, de pérdida.

La realidad histórica se ve tergiversada, pero, al menos, el poeta ha sabido distinguir entre lo que era la tierra, el solar, de llegada de Tarik, esto es, Iberia, y en lo que llegó a convertirse antes de la ida del último árabe, lo que en su perspectiva es ya España.

El poeta, ese criollo que medita sobre la imagen del árabe y su historia, le tiende la mano y declara abiertamente su solidaridad: ambos han compartido una historia afín, ambos comparten un presente de pérdida, ¿por qué no vagar juntos hasta hallar 
una luz que les ilumine? Aquí, creo, radica el aporte, el suyo, personal, de Emilio Mohor: más allá de la historia, de la geografía, existen los lazos espirituales, incluso religiosos; más allá de las confesiones, a los seres humanos, a los pueblos, pueden unirles causas y sentimientos comunes.

Degustemos ahora el segundo poema que trata el tema, titulado precisamente "Tarik":

Año setecientos once...

Gritos de guerra sonaron

en las arenas de cobre

¡Allah-u-Akbar!

Tarik dirige sus huestes

hacia la tierra cristiana

lleva los hombres más fuertes

que diera la noble Arabia.

Tarik garboso camina

por las arenas de África.

Trescientos regios varones

lleva consigo la hazaña.

-¿Varones?- Digo leones,

que quieren tomar España.

$\mathrm{Y}$ doce mil berberiscos

que forman la retaguardia.

Por el cielo turquí corren albores de la mañana, los rayos del sol cabriolan en el filo de las lanzas.

El mar Ibérico espera

a los señores de Allah.

En bellas naves doradas

llegan a tierra cristiana.

El jefe ordena incendiar

los barcos de la jornada.

Hecho que siglos más tarde

Hernán Cortés imitara.

Don Rodrigo y visigodos

en la tierra jerezana...

El horizonte se enciende

con el fragor de las armas.

Tarik gravoso camina

Por las tierras de Granada. 


\begin{abstract}
Bermejo se torna el cielo como corazón de grana, los alfanjes refulgían con las carnes destrozadas.

Polvillo fino de oro ahogaba las gargantas.

Cimitarras y gumías, rubí de sangre cristiana.

Al aclarar la mañana

Don Rodrigo agonizaba.

Tarik gravoso camina por el jardín de Granada» ${ }^{21}$.
\end{abstract}

El poema, conformado por versos octosílabos dispuestos en estrofas combinadas de cuatro y dos versos, se centra particularmente en la visión histórica a partir de dos personajes singulares: el ya aludido Tarik y el conquistador Hernán Cortés.

En realidad, la mirada es básicamente la misma: un hecho histórico - a partir de una perspectiva más o menos distorsionada, poética, subjetiva- es revivido, o parangonado, con otro similar, mas sucedido en otro tiempo histórico y en tierras lejanas. Acaso sea una forma para explicar el presente mediante el pasado, y de acercar las orillas de mares y océanos: el Atlántico, según nos cuenta Mohor, poco difiere del Mediterráneo.

Como análisis global a su sentir andalusí, valga la expresión, tal vez el punto a resaltar sea el deseo de encontrar vínculos, lazos, a partir básicamente de la historia y sus personajes, entre la vieja Europa y el Nuevo Mundo. Y no sólo en la perspectiva histórica, sino también en la puramente sociológica, aquella que se ocupa de los pueblos y sus porqués, sus planteamientos y comportamientos.

Emilio Mohor, en último caso, lo que hace es vincular su situación, su realidad presente - en tanto que chileno de origen árabe, en tanto que latinoamericano con raíces mediterráneas - con la pasada, la originaria. En este sentido, cabe mencionar que se inscribe en una línea de visión histórica muy presente en América Latina, y en Chile particularmente. En realidad, su planteamiento, su evocación de Alándalus, y dejando un tanto al margen las pautas poéticas, se dirige a uno de los temas en la cresta de la ola en América Latina, y principalmente acaso en el sur: la cuestión de la identidad.

Alándalus, entonces, no sólo será realidad poética en sí, sino que, además, se torna vínculo sólido con su raíz árabe: atestigua su identidad.

${ }^{21}$ MARTÍNEZ LILLO, Rosa-Isabel, Alándalus..., 102-103. 


\subsection{OLGA LOLAS NAZRALA}

Nacida el 28 de febrero de 1927 en la aldea de San Felipe, y también de origen palestino, Olga Lolas es prototipo no sólo de poetisa, sino de artista en toda su extensión y plenitud. En cuanto a sus estudios académicos, cursa Pedagogía en Castellano en el Instituto Pedagógico de la Universidad de Chile, estudios que compagina desde el principio con su actividad creativa, valorada muy positivamente desde una temprana edad por críticos tan eminentes como Matías Rafide:

En sus libros fluye la poesía espontáneamente, sin esfuerzo, como el agua de las grandes vertientes. Tiene aciertos poéticos bellísimos [...] de una imaginación incomparable $[\ldots]$ A pesar de las vacilaciones propias de su juventud, se nos aparece como auténtico valor, de positivos méritos. Creemos en Olga Lolas y le auguramos un futuro brillante en las letras nacionales ${ }^{22}$.

Se doctora en Madrid - en la entonces Universidad Central, ahora Complutensey viaja por España, principalmente por Andalucía. Precisamente será Andalucía, que la propia Olga vincula al oriente árabe, una de sus fuentes de inspiración más evocadoras; Córdoba con su Plaza del Cristo de los Faroles, Granada de pérdidas y llantos con su Alhambra engalanada de oropeles y umbral de amarguras...dos ciudades señeras que la artista sentirá en lo más hondo de sus entrañas y que, en definitiva y a la par que el viaje por la España eminentemente castellana y un oriente exótico e imaginario, asociará a Alándalus.

En cuanto a sus obras, destacan el poemario Tarika-el-Kamar, -El Camino a la luna en su propia traducción (1943) - y Cuando muere el plenilunio (1949), conjunto de relatos escrito a manera de prosa poética.

A pesar de haber publicado solamente estas dos obras poéticas, Olga Lolas, ya apartada de la actividad docente — que en los últimos años desempeñó en San Felipe - sigue comprometida con la causa palestina, haciéndose escuchar en la prensa local y viviendo por y para el arte en su mágica casa que le viera nacer.

En fin, ¿cómo siente Olga Lolas Alándalus? El poema a continuación, significativamente titulado "La postrera sombra" nos ofrece claramente su mirada:

Yo no he llegado nunca

hasta el desierto

y sin embargo

vengo del "hasta"

del confín sin nombre

donde el sol

se derrama

hasta alcanzar

los pies dormidos

de la Media Luna.

${ }^{22}$ RAFIDE BATARCE, Matías, Escritores chilenos..., 181-183. 
Yo vengo de la

pupila de un sueño

del fragor del

corazón reposando

en los aljibes

hondos, milenarias

penumbras donde

siguen pasando

y pasando

por mi sangre

las caravanas insomnes

del destino.

Hago sonar mi voz

y un golpe de luz

convoca los silencios

de los que vendrán

a cosechar la muerte

y su siembra de promesa

floreciendo.

Los ojos del espanto partieron las piedras

y la pasajera sombra del recuerdo se quedó

colgando de las ramas

de un árbol seco

mientras la sangre delirante

buscaba el seno

de la tierra

donde ya la muerte

no tiene nombre

ni figura.

Sólo destino es su poder terrible, sólo el grito

llegando a lo sin linde

despertando en pueblo

su florecer

de raíz

y de agua viva

para amparar

a los sedientos

respondiendo

a los mudos

ojos del amor

sin mengua 
y a su nunca
consumida
palabra.

Aquí o allá la arena ciega por igual no canta no dice ni sabe cuando los plazos vencen o puede el viento despertar a los muertos.

Porque sólo lo solo del que sufre espera el oasis final la llaga verde.

Caminantes me llamo caminantes somos voy buscando mi huella por la arena interrogando a los ojos de los camellos y sólo me abren la ruta de los anchos cielos a su carga de sombras.

Mi padre y mi madre son toda tierra anduve por las manos de mi padre y en los ojos de mi madre creció la lejanía.

Estuvo mi sombra en los miradores de Granada $\mathrm{Y}$ el Cristo de los Faroles me encontró en su noche.

Me surge de la bruma desierto y camino siempre el vivir en trance 


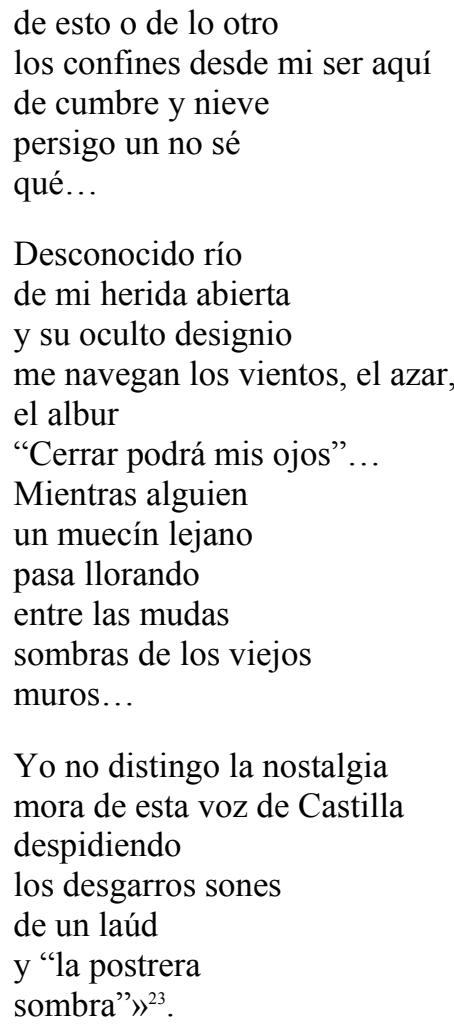

En este extenso poema de verso libre, como acostumbra la poetisa, si bien las referencias históricas aparecen, aunque quizá más solapadamente, el elemento fundamental va a ser el espacial, la geografía; una geografía, unos espacios que la propia Lolas vive y recrea en primera persona: se trata de espacios no sólo sentidos en la lejanía, sino de espacios vividos, cuyo aire respiró.

La dimensión física, entonces, será el eje del poema: el desierto, los aljibes, alternan sus apariciones con ciudades como Granada y Córdoba, representada por la bella plaza del Cristo de los faroles.

La autora, en este deseo de búsqueda física, de tierra, vuelve la mirada a sus padres - llegados de Palestina - y, con la nostalgia también como pulsión eterna del corazón árabe, rememora aquellas tierras de Granada y de Córdoba; tierras ora de destierro, ora de acogida. Mas no olvida aquella otra dimensión física que vivió, en experiencia vital y académica: Castilla. Y es que, además, de su profesado amor por Quevedo, Lolas encuentra en Castilla, siguiendo en cierto modo los pasos de la Generación del 98, el contrapunto a los oropeles y brillos propiamente sureños.

${ }^{23}$ MARTÍNEZ LILLO, Rosa-Isabel, Alándalus..., 124-127. 
En definitiva, y reincidiendo en su mirada de tintes más geográficos, quizá el aspecto más genuino de su Alándalus sea tal perspectiva de dimensión castellanoandaluza, muy impregnada de literatura, de poesía.

\section{CONCLUSIONES: Y QUEDA...}

A modo de conclusión, se podría destacar:

1-En primer lugar, y de manera global, la perspectiva de índole subjetiva, evocadora, como cabría esperar, por otra parte, de cualquier obra poética.

2-En segundo lugar, se inscribe en la realidad espacio-temporal en que se produce: la realidad de Chile y su literatura. El hecho de vincular al criollo, como hacía Mohor, con otros pueblos - frutos de mezcla - es una constante en numerosos países de América Latina, y en Chile particularmente. Identificar al último omeya que llega a la Península Ibérica en el año 711 con el emigrante árabe que llega a América a finales del siglo XIX, a la par que reivindicar la sangre árabe que llega allá en las naos de los conquistadores a partir de 1492, son constantes en las miradas no sólo literarias sino incluso históricas de América Latina, y particularmente en el país andino.

3-En tercer lugar, y muy a la par que el punto anterior, el deseo de identificación, esto es, la cuestión de la identidad. Ambos autores recrean Alándalus buscando, patente o latentemente, sus orígenes en tanto que árabes. Si bien Mohor, como se vio, apuntaba a hechos y personajes históricos, Lolas lo hará aludiendo preferentemente a espacios.

4-En cuarto lugar, finalmente, el sentimiento último de pérdida: la alusión a Granada. En ambos poetas, como apreciamos, se llega a Granada, al punto final de aquello que quizá pudo haber sido, mas nunca terminó de consumarse.

Queda, así, el último reino andalusí como vínculo entre los poetas chilenos de origen árabe y Alándalus, acaso como acaeciera con la historia:

El reino nazarí, en los siglos XIII y XIV, fue el último andalusí, sobre el cual vino a instalarse una nueva dinastía sin nexos anteriores y formando un estado sin antecedentes en la geopolítica andalusí [...] y, por primera y última vez, un linaje andalusí que mantuvo estable un Estado durante tiempo extenso, por causas exteriores, ante las cuales Granada supo usar una suave diplomacia, e interiores, pues los territorios restantes se apiñaron para sobrevivir, recibiendo un beneficioso éxodo de andalusíes, cuyas tierras iban siendo conquistadas, y que dieron a este reino nazarí su inicial densidad de población y su intensificación productiva ${ }^{24}$.

${ }^{24}$ MARTÍNEZ MONTÁVEZ, Pedro, Significado y Símbolo de Al-Ándalus, Granada, 2011, 216-7, tomado de VIGUERA MOLINS, María Jesús, Historia de las Españas medievales, Barcelona, 2002, 243-5. 
Como Granada, Alándalus va desapareciendo en los divanes de los poetas chilenos de origen árabe.

Resulta sorprendente, o quizá sólo inesperado, constatar cómo dicho tema, Alándalus, va disipándose lentamente, borrándose del imaginario de las nuevas generaciones. Si desde que llegara Benedicto Chuaqui, como se indicaba al principio del estudio, hasta nuestros días, el tema de Alándalus en sí fue tocado solamente por los dos poetas aludidos y como fuente de inspiración de tres poemas, cabe señalar que, tras ellos, pareciera Alándalus hubiera desaparecido en la noche de los tiempos ${ }^{25}$.

Como sello, permítaseme incluir las cálidas palabras de Jessica $\mathrm{Atal}^{26}$, también escritora chilena de origen árabe, quien, al ser interrogada sobre Alándalus, abrió de par en par las puertas de su corazón:

Significa mil y una cosas tanto en mi corazón de árabe como en mi poesía. Allí están las relaciones que los árabes tienen con toda América. Y allí la cultura árabe dejó huellas tan profundas que cambiaron la historia cultural, económica, social y artística tanto de Europa como de América. El desarrollo cultural que existió a comienzos de la Edad Media en el califato de Córdoba y emirato de Granada es de una riqueza valiosísima.[...]En lo más íntimo, Al-Ándalus significa para mí misterio, grandeza, fuerza, pero también lo asocio con un rincón privado de mi alma, con momentos de recogimiento y reflexión, y un lugar seguro de profunda inspiración ${ }^{27}$.

${ }^{25}$ Siendo los centros de investigación principales: Centro de Estudios Árabes de la Universidad de Chile, biblioteca particular de Matías Rafide, biblioteca particular de Olga Lolas, biblioteca particular de Naín Nómez y biblioteca particular de Walter Garib, así como los testimonios personales de los mismos y los de Velia y Rubén Chuaqui.

${ }^{26}$ De padre sirio y madre palestina, es una joven poeta y colaboradora del diario El Mercurio; de entre sus poemarios destacamos Variaciones en azul profundo, Santiago de Chile, 1991, y Pérdida, Santiago de Chile, 2010. Acaba de sacar un ensayo titulado Arquetipos, Santiago de Chile, 2013.

${ }^{27}$ MARTÍNEZ LILLO, Rosa-Isabel, Alándalus ... , 159-160. 